\title{
Synthesis, Crystal Structure, and DFT Calculations of 1,3-Diisobutyl Thiourea
}

\author{
Ataf A. Altaf, ${ }^{1}$ Adnan Shahzad, ${ }^{2}$ Zarif Gul, ${ }^{2}$ Sher A. Khan, ${ }^{2}$ Amin Badshah, ${ }^{3}$ \\ Muhammad N. Tahir, ${ }^{4}$ Zafar I. Zafar, ${ }^{5}$ and Ezzat Khan ${ }^{2}$ \\ ${ }^{1}$ Department of Chemistry, Government College University, Faisalabad 38000, Pakistan \\ ${ }^{2}$ Department of Chemistry, University of Malakand, Dir Lower, Khyber Pakhtunkhwa, Chakdara 18550, Pakistan \\ ${ }^{3}$ Department of Chemistry, Quaid-i-Azam University, Islamabad 45320, Pakistan \\ ${ }^{4}$ Department of Physics, University of Sargodha, Sargodha, Punjab 40100, Pakistan \\ ${ }^{5}$ Inorganic Chemistry Division, Institute of Chemical Sciences, Bahauddin Zakariya University, Multan 60800, Pakistan \\ Correspondence should be addressed to Ataf A. Altaf; atafali_altaf@yahoo.com and Ezzat Khan; ekhan@uom.edu.pk
}

Received 13 November 2014; Revised 5 February 2015; Accepted 12 February 2015

Academic Editor: Marc Visseaux

Copyright (C) 2015 Ataf A. Altaf et al. This is an open access article distributed under the Creative Commons Attribution License, which permits unrestricted use, distribution, and reproduction in any medium, provided the original work is properly cited.

1,3-Diisobutyl thiourea was synthesized and characterized by single crystal X-ray diffraction. It gives a monoclinic $(\alpha=\gamma=90$ and $\beta \neq 90$ ) structure with the space group P21/c. The unit cell dimensions are $a=11.5131$ (4) $\AA, b=9.2355$ (3) $\AA, c=11.3093$ (5) $\AA, \alpha=$ $90^{\circ}, \beta=99.569^{\circ}(2), \gamma=90^{\circ}, V=1185.78(8) \AA^{3}$, and $Z=4$. The crystal packing is stabilized by intermolecular $(\mathrm{N}-\mathrm{H} \cdots \mathrm{S})$ hydrogen bonding in the molecules. The optimized geometry and Mullikan's charges of the said molecule calculated with the help of DFT using B3LYP-6-311G model support the crystal structure.

\section{Introduction}

Thiourea derivatives are well known sulphur containing compounds acting as ligands in the field of coordination chemistry [1-3]. Such ligands are capable of affording complexes with metal ions; the resultant complexes have been reported to have imperative antimicrobial [4] and anticonvulsant [5] applications. Thiourea derivatives and their complexes have numerous catalytic applications in asymmetric organocatalysis [6-8], have been used as cocatalysts in Pauson-Khand reactions [1], Pd-catalyzed reactions [1, 9], Heck and Suzuki coupling reactions, and so forth $[2,9]$. Thiourea derivatives got much more attention in the field of highly enantio- and diastereoselective catalysis [10] and have also been applied as cocatalysts in nanoparticles and a number of other types of reactions [11, 12]. The challenging task in the chemistry of thiourea is its syntheses and structural characterization. Several research groups are trying to make this versatile group of compounds easily accessible and have reported various methods [13-16].
In continuation to our previous work [17] the title compound was obtained unexpectedly. Surprisingly a comprehensive research survey does not show solid state structural data of title compound $\mathbf{1}$. The structure of the compound was determined by X-ray diffraction and its DFT optimized geometry was determined using B3LYP-6311G model of theory [18]. Theoretical data obtained for the compound compare well with the experimental data.

\section{Experimental}

All chemicals, that is, carbon disulphide and isobutyl amine, are commercially available and were used without further purification. Solvents were distilled prior to use.

2.1. Synthesis of 1,3-Di(isobutyl)thiourea. Solution of carbon disulphide ( $498.0 \mathrm{mmole} ; 50 \mathrm{~mL}$ ) was prepared in petroleum ether $(100 \mathrm{~mL})$ and was cooled to $0^{\circ} \mathrm{C}$ in an ice bath, following 


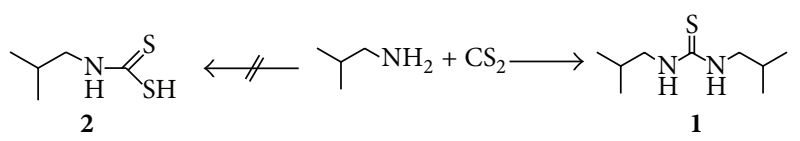

Scheme 1: Reaction between $\mathrm{CS}_{2}$ and isobutylamine to afford 1,3diisobutyl thiourea.

the literature procedure $[16,17]$. An excess amount of isobutylamine (996.0 mmole; $61.42 \mathrm{~mL}$ ) was slowly and carefully added with constant stirring. The stirring was continued overnight. The solvent and all other volatiles were removed under reduced pressure and the oily compound was dissolved in ethyl acetate. After 2 days needle-like colorless crystals appeared in the solution; they were further allowed for few days to grow well. The same reaction was repeated by mixing equimolar amounts of $\mathrm{CS}_{2}$ and isobutylamine by adopting the same procedure but instead of the expected dithiocarbamate 2 , product 1 was exclusively obtained (Scheme 1 ).

2.2. X-Ray Crystallography. A crystal of suitable dimensions was selected for X-ray structure analysis. The diffraction intensity data were collected on a Bruker kappa APEXII CCD diffractometer using graphite-monochromator Mo-K $\alpha$ radiation $(\lambda=0.71073 \AA)$ at ambient temperature. For data collection $\omega$ scan and multiscan absorption correction was applied. Final refinement on $F^{2}$ was carried out by full-matrix least-squares techniques. Structure solution and refinements were accomplished with SHELXL-97 [19] and publCIF [20].

2.3. DFT Calculations. The geometry of title compound (1) was obtained from X-ray crystallographic data. The molecular structure of (1) $\left(\mathrm{C}_{9} \mathrm{H}_{20} \mathrm{~N}_{2} \mathrm{~S}\right)$ in ground state is optimized by DFT method including correlation correction using B3LYP-6311G model of theory [18]. Mullikan's charges were calculated by using the same model of theory; the data so-obtained are given in Table 5 and optimized structure of the compound is given in Figure 2. All calculations were performed by using Gauss-view molecule visualizer program and GAUSSIAN-03 program $[18,21,22]$.

\section{Results and Discussion}

The reaction of primary or secondary amines with carbon disulphide gives dithiocarbamates; the reaction is straightforward and usually proceeds without the formation of side products. We treated isobutylamine with carbon disulphide in petroleum ether and instead of dithiocarbamate derivative 2 , compound 1 was exclusively obtained as solid (Scheme 1). The reaction proceeded at ambient temperature without adding a catalyst and excellent yield was achieved. The reaction probably proceeds through formation of isothiocyanate intermediate which reacts further with amine and rearranges to thiourea [16].

Single Crystal Studies. The molecular structure of compound $\mathbf{1}$ is given in Figure 1 with numbering scheme. It crystallizes in monoclinic crystal system $(\alpha=\gamma=90, \beta \neq 90)$ with the space group P21/c; the crystal packing in unit cell is stabilized
TABLE 1: Crystal data and structure refinement.

\begin{tabular}{|c|c|c|}
\hline Crystal parameter & & Value \\
\hline Empirical formula & & $\mathrm{C}_{9} \mathrm{H}_{20} \mathrm{~N}_{2} \mathrm{~S}$ \\
\hline Formula weight & & 188.34 \\
\hline Temperature & & $296 \mathrm{~K}$ \\
\hline Wavelength & & $0.71073 \AA$ \\
\hline Crystal system & & Monoclinic \\
\hline Space group & & $\mathrm{P} 21 / \mathrm{c}$ \\
\hline \multirow{4}{*}{ Unit cell dimensions } & $a$ & $11.5131(4) \AA$ \\
\hline & $b$ & $9.2355(3) \AA$ \\
\hline & $c$ & $11.3093(5) \AA$ \\
\hline & $\beta$ & $99.569(2)$ \\
\hline Volume & & $1185.78(8) \AA^{3}$ \\
\hline $\mathrm{Mu}$ & & $0.232 \mathrm{~mm}^{-1}$ \\
\hline$Z$, density & & $4,1.055 \mathrm{~g} \mathrm{~cm}^{-3}$ \\
\hline$F(0,0,0)$ & & 416.0 \\
\hline$(h, k, l) \min$ & & $(-13,-9,-13)$ \\
\hline$(h, k, l) \max$ & & $(13,11,13)$ \\
\hline Correction method & & Multiscan \\
\hline Theta $(\max )$ & & 25.250 \\
\hline$R$ (reflection) & & $0.0716(1637)$ \\
\hline$w R_{2}$ & & $0.2021(2145)$ \\
\hline Data completeness & & 1.000 \\
\hline Goodness of fit & & 1.053 \\
\hline
\end{tabular}

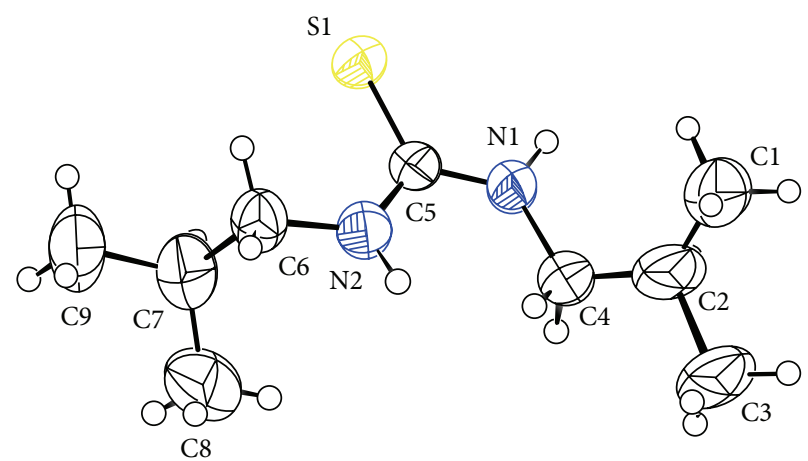

FIGURE 1: Crystal structure (ORTEP plot) of 1,3-diisobutyl thiourea molecule with labeling scheme.

by intermolecular $\mathrm{N}-\mathrm{H}$... S bonding with an average distance of $2.819 \AA$, which is relatively stronger than the reported one $2.87 \AA[23]$ and is closer to $2.837 \AA$ [24]. The data pertinent to crystal structure determination are summarized in Table 1.

The geometry around nitrogen atom is distorted and cannot be predicted on the basis of hybridization. The distortion can easily be traced out by the involvement of lone pair of electrons on nitrogen in delocalization phenomenon with the $\pi$ electrons of $\mathrm{C}=\mathrm{S}$ moiety. The $\mathrm{C} 5-\mathrm{N} 1$ bond distance $(1.328 \AA)$ and $\mathrm{C} 5-\mathrm{N} 2(1.343 \AA)$ are shorter than average C$\mathrm{N}$ single bond distance $(1.499 \AA)$ and similarly that of $\mathrm{C}=\mathrm{S}$ bond distance $(1.698 \AA)$ is longer than the average distance $(1.599 \AA)$ reported in literature [25]. These data support partial double bond characters between $\mathrm{N} \cdots \mathrm{C}$ and flow of 
TABLE 2: Hydrogen bonding data for the title compound.

\begin{tabular}{lcccccc}
\hline $\mathrm{X}$ & $\mathrm{H}$ & $\mathrm{Y}$ & $d(\mathrm{X}-\mathrm{H})(\AA)$ & $d(\mathrm{H}-\mathrm{Y})(\AA)$ & $d(\mathrm{X}-\mathrm{Y})(\AA)$ & $<(\mathrm{XHY})\left(^{\circ}\right)$ \\
\hline $\mathrm{N} 1$ & $\mathrm{H} 1 \mathrm{a}$ & $\mathrm{S} 1$ & $0.861(4)$ & $2.683(8)$ & $3.479(2)$ & $154.33(3)$ \\
$\mathrm{N} 2$ & $\mathrm{H} 2 \mathrm{a}$ & $\mathrm{S} 1$ & $0.860(4)$ & $2.819(3)$ & $3.573(3)$ & $147.37(5)$ \\
\hline
\end{tabular}

TABLE 3: Selected bond lengths (experimental and calculated) belong to compound $\mathbf{1}$.

\begin{tabular}{lcc}
\hline Bonded atoms & Experimental & Calculated \\
\hline S1-C5 & $1.698(3)$ & 1.7375 \\
N1-C5 & $1.328(4)$ & 1.3665 \\
N1-C4 & $1.452(4)$ & 1.4664 \\
N2-C5 & $1.343(4)$ & 1.3624 \\
N2-C6 & $1.455(4)$ & 1.4683 \\
C1-C2 & $1.419(7)$ & 1.5385 \\
C2-C4 & $1.378(6)$ & 1.5444 \\
C2-C3 & $1.542(6)$ & 1.5379 \\
C6-C7 & $1.488(6)$ & 1.5420 \\
C7-C8 & $1.490(7)$ & 1.5409 \\
C7-C9 & $1.536(6)$ & 1.5417 \\
\hline
\end{tabular}

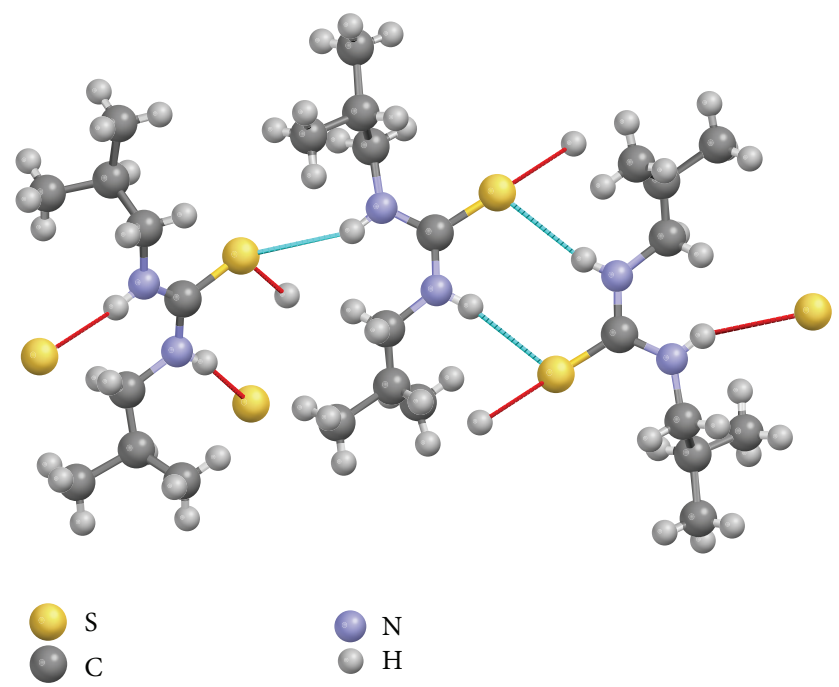

FIGURE 2: The packing of thiourea (1) molecules showing the intermolecular $\mathrm{H}$-bonding.

electron density from sulfur resulting in an elongation in S-C bond.

The elongation of $\mathrm{C}-\mathrm{S}$ bond may also be explained on the basis of intermolecular hydrogen bonding (data reported in Table 2). The solid state crystal packing and intermolecular interactions are shown in Figure 2. The molecules of the title compound are organized and held together with the help of intermolecular $\mathrm{N}-\mathrm{H} \cdots \mathrm{S}$ hydrogen bonding with an average distance $2.819 \AA$, which falls in the expected range, reported for analogous compounds, that is, $2.87 \AA$ [23], $2.84 \AA$ [26], and $2.837 \AA$ [24]. The experimental and calculated data (for gaseous molecule), DFT (B3LYP/6-311G), are given in Table 3. The calculated and experimental data related to bond
TABLE 4: Selected bond angles and torsion angles for compound 1, a comparison between experimental and theoretical data.

\begin{tabular}{lcc}
\hline Atoms & Experimental & Calculated \\
\hline & Bond angle & \\
C1-C2-C3 & $112.9(4)$ & 111.391 \\
C1-C2-C4 & $125.8(5)$ & 109.523 \\
C4-C2-C3 & $110.5(4)$ & 111.876 \\
C2-C4-N1 & $117.7(4)$ & 114.192 \\
C4-N1-C5 & $126.4(3)$ & 125.221 \\
N1-C5-S1 & $120.3(3)$ & 123.101 \\
S1-C5-N2 & $122.4(3)$ & 122.101 \\
N1-C5-N2 & $117.2(3)$ & 114.798 \\
C5-N2-C6 & $125.2(3)$ & 129.550 \\
N2-C6-C7 & $114.4(3)$ & 112.036 \\
C6-C7-C8 & $113.3(4)$ & 112.558 \\
C6-C7-C9 & $109.0(4)$ & 112.701 \\
C9-C7-C8 & $110.9(4)$ & 111.702 \\
\hline & Torsion angle & \\
C4-N1-C5-S1 & 171.91 & 170.09 \\
S1-C5-N2-C6 & 0.22 & 0.91 \\
C5-N1-C4-C2 & 150.89 & 149.07 \\
C5-N2-C6-C7 & 89.97 & 85.70 \\
N1-C4-C2-C1 & 43.49 & 45.76 \\
N1-C4-C2-C3 & 175.10 & 173.75 \\
N2-C6-C7-C8 & 60.57 & 60.73 \\
N2-C6-C7-C9 & 175.35 & 175.26 \\
\hline
\end{tabular}

angles around $\mathrm{N}$ atom are approximately $120^{\circ}$ which support the planarity and $\mathrm{sp}^{2}$ hybridization around nitrogen owing to delocalization of electrons in the molecule.

DFT-Studies and Vibrational Spectra Analysis. Experimental data correspond to solid phase while theoretical calculations belong to gaseous phase [22]. DFT calculations are usually performed on a single molecule in the unit cell [27]. DFT calculations for compound $\mathbf{1}$ were carried out by using the GAUSSIAN-03 program [18, 21, 22]. The geometry of the molecule was optimized by DFT/B3LYP with the 6-311G basis set [18]. The optimized geometry obtained through DFT was compared with crystal structure which supports the crystal structure. The crystallographic and optimized geometric bond lengths and bond angles of compound $\mathbf{1}$ are given in Tables 3 and 4, respectively.

Mullikan's charges distribution on atoms of compound (1) is given in Table 5. It can be noticed from the table that negative charge density of nitrogen and terminal carbon appears in the range of -0.660 and -0.508 , respectively, which is considerably larger than other atoms bearing negative 
TABLE 5: Calculated Mullikan's charges for B3LYP/6-311G.

\begin{tabular}{lc}
\hline Atoms & B3LYP/6-311G \\
\hline C1 & -0.508 \\
H1A & 0.168 \\
H1B & 0.187 \\
H1C & 0.177 \\
C2 & -0.190 \\
H2 & 0.218 \\
C3 & -0.512 \\
H3A & 0.166 \\
H3B & 0.161 \\
H3C & 0.181 \\
C4 & -0.161 \\
H4A & 0.164 \\
H4B & 0.238 \\
N1 & -0.660 \\
HI & 0.314 \\
C5 & 0.279 \\
S1 & -0.163 \\
N2 & -0.664 \\
H2(N) & 0.309 \\
C6 & -0.111 \\
H6A & 0.225 \\
H6B & 0.219 \\
C7 & -0.291 \\
H7 & 0.194 \\
C8 & -0.486 \\
H8A & 0.186 \\
H8B & 0.157 \\
H8C & 0.188 \\
C9 & -0.492 \\
H9A & 0.180 \\
H9B & 0.183 \\
H9C & 0.155 \\
\hline & \\
\hline &
\end{tabular}

charges, which shows that nitrogen is donor sites for traditional and terminal carbons are donor sites for nontraditional hydrogen bonding.

The experimental and calculated (B3LYP/6-311G) IR absorption frequency along with their respective intensities are given in Figure 3. The experimental bands are probably assigned comparatively with related molecules [28]. The presence of intermolecular interactions is responsible for the higher value of $v(\mathrm{C}=\mathrm{S})$ stretching at $1227 \mathrm{~cm}^{-1}$. The absorption bands at 3346 and $3237 \mathrm{~cm}^{-1}$ are representing $\nu\left(\mathrm{N}_{1}-\mathrm{H}\right)$ and $\nu\left(\mathrm{N}_{2}-\mathrm{H}\right)$ stretching for title compound (1); their corresponding quantum chemical calculated $\nu(\mathrm{N}-\mathrm{H})$ stretching appeared to be shifted to higher frequency. The bands at $2954-2868 \mathrm{~cm}^{-1}$ are assigned to $\nu(\mathrm{C}-\mathrm{H})$ stretching similar to the calculated one. Strong IR bands in range 1600$1500 \mathrm{~cm}^{-1}$ represent $\nu(\mathrm{N}-\mathrm{H})$ bending [29]. In addition strong band at $1227 \mathrm{~cm}^{-1}$ corresponds to $\nu(\mathrm{C}=\mathrm{S})$ stretching. Lower value of $v(C=S)$ up to $750 \mathrm{~cm}^{-1}$ is also reported $[29,30]$ but

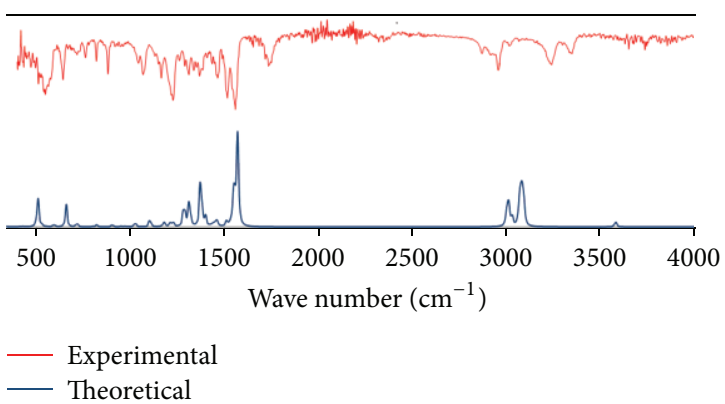

FIGURE 3: Comparative infrared spectra of the title compound in the gaseous state (theoretical, calculated using B3LYP/6-311G method) and in the solid state (experimental).

intermolecular $\mathrm{C}=\mathrm{S} \cdots \mathrm{H}-\mathrm{X}$ interaction strongly affects the $\mathrm{C}=\mathrm{S}$ stretching [30].

\section{Conclusions}

Reaction of $\mathrm{CS}_{2}$ and isobutylamine affords the corresponding thiourea instead of dithiocarbamate derivative. The compound could easily be purified with the help of crystallization. The crystal structure studies show the existence of intermolecular $\mathrm{N}-\mathrm{H}$...S type H-bonding. All structural parameters were also calculated (DFT) and were compared with the experimental data. Solid state and gaseous phase data (bonding and vibration energies) are in close agreement with each other.

\section{Conflict of Interests}

The authors declare that there is no conflict of interests regarding the publication of this paper.

\section{Acknowledgment}

This work was supported by Higher Education Commission of Pakistan, under NRPU Project no. 20-1488/R\&D/09-5432.

\section{References}

[1] Y. Tang, Y. Zhang, M. Dai et al., "A highly efficient synthesis of the FGH ring of micrandilactone A. application of thioureas as ligands in the co-catalyzed Pauson-Khand reaction and Pdcatalyzed carbonylative annulation," Organic Letters, vol. 7, no. 5, pp. 885-888, 2005.

[2] W. Chen, R. Li, B. Han et al., "The design and synthesis of bis(thiourea) ligands and their application in Pd-catalyzed heck and suzuki reactions under aerobic conditions," European Journal of Organic Chemistry, no. 5, pp. 1177-1184, 2006.

[3] J. Liu, B. Liang, D. Shu, Y. Hu, Z. Yang, and A. Lei, "Alkoxycarbonylation of aryl iodides catalyzed by Pd with a thiourea type ligand under balloon pressure of CO," Tetrahedron, vol. 64, no. 40, pp. 9581-9584, 2008.

[4] H. Arslan, N. Duran, G. Borekci, C. K. Ozer, and C. Akbay, "Antimicrobial activity of some thiourea derivatives and their 
nickel and copper complexes," Molecules, vol. 14, no. 1, pp. 519527, 2009.

[5] A. Ö. Çelen, B. Kaymakçığlu, S. Gümrü, H. Z. Toklu, and F. Aricioğlu, "Synthesis and anticonvulsant activity of substituted thiourea derivatives," Marmara Pharmaceutical Journal, vol. 15, no. 2, pp. 43-47, 2011.

[6] S. J. Connon, "Asymmetric catalysis with bifunctional cinchona alkaloid-based urea and thiourea organocatalysts," Chemical Communications, no. 22, pp. 2499-2510, 2008.

[7] M. Frings, I. Thomé, and C. Bolm, "Synthesis of chiral sulfoximine-based thioureas and their application in asymmetric organocatalysis," Beilstein Journal of Organic Chemistry, vol. 8, pp. 1443-1451, 2012.

[8] T. E. Shubina, M. Freund, S. Schenker, T. Clark, and S. B. Tsogoeva, "Synthesis and evaluation of new guanidine-thiourea organocatalyst for the nitro-Michael reaction: theoretical studies on mechanism and enantioselectivity," Beilstein Journal of Organic Chemistry, vol. 8, pp. 1485-1498, 2012.

[9] D. Mingji, B. Liang, C. Wang et al., "A novel thiourea ligand applied in the Pd-catalyzed Heck, Suzuki and Suzuki carbonylative reactions," Advanced Synthesis and Catalysis, vol. 346, no. 13-15, pp. 1669-1673, 2004.

[10] T. Bui, S. Syed, and C. F. Barbas III, "Thiourea-catalyzed highly enantio- and diastereoselective additions of oxindoles to nitroolefins: application to the formal synthesis of (+)physostigmine," Journal of the American Chemical Society, vol. 131, no. 25, pp. 8758-8759, 2009.

[11] S. Hegde, S. S. Joshi, T. Mukherjee, and S. Kapoor, "Photochemical synthesis of gold nanoparticles in $N, N^{\prime}$-dimethylformamide via thiourea-derivatized polyoxometalate," Research on Chemical Intermediates, vol. 40, no. 3, pp. 1125-1133, 2014.

[12] X. Han, J. Kwiatkowski, T. Xue, K.-W. Huang, and Y. Lu, "Asymmetric mannich reaction of fluorinated ketoesters with a tryptophan-derived bifunctional thiourea catalyst," Angewandte Chemie - International Edition, vol. 48, no. 41, pp. 76047607, 2009.

[13] E. C. Taylor and R. V. Ravindranathan, "Reaction of anthranilonitrile and $\mathrm{N}$-methylanthranilonitrile with phenyl isocyanate and phenyl isothiocyanate," The Journal of Organic Chemistry, vol. 27, no. 7, pp. 2622-2627, 1962.

[14] P. Pazdera, E. Nováček, and D. Ondrácek, "A new knowledge about the synthesis of 1-phenyl-3-(2-cyanophenyl) thiourea," Chemical Papers, vol. 43, pp. 465-470, 1989.

[15] W. Fathalla, M. Čajan, J. Marek, and P. Pazdera, "One-pot quinazolin-4-yl-thiourea synthesis via $N$-(2-cyanophenyl)benzimidoyl isothiocyanate," Molecules, vol. 6, no. 7, pp. 588-602, 2001.

[16] N. Azizi, A. Khajeh-Amiri, H. Ghafuri, and M. Bolourtchian, "Toward a practical and waste-free synthesis of thioureas in water," Molecular Diversity, vol. 15, no. 1, pp. 157-161, 2011.

[17] E. Khan, A. Badshah, and R. Kempe, "Synthesis and molecular structure of bis(4-methylpiperidinodithiocarbamato) nickel(II)," Journal of the Chemical Society of Pakistan, vol. 32, no. 3, pp. 349-352, 2010.

[18] A. Moores, L. Ricard, and P. Le Floch, "Al-methyl-phosphininium compound: synthesis, X-ray crystal structure, and DFT calculations," Angewandte Chemie, vol. 42, no. 40, pp. 49404944, 2003.

[19] G. M. Sheldrick, "A short history of SHELX," Acta Crystallographica Section A: Foundations of Crystallography, vol. 64, no. 1, pp. 112-122, 2007.
[20] S. P. Westrip, "PublCIF: software for editing, validating and formatting crystallographic information files," Journal of Applied Crystallography, vol. 43, no. 4, pp. 920-925, 2010.

[21] R. Dahiya and D. Pathak, "Synthetic studies on novel benzimidazolopeptides with antimicrobial, cytotoxic and anthelmintic potential," European Journal of Medicinal Chemistry, vol. 42, no. 6, pp. 772-798, 2007.

[22] Ç. Yüksektepe, N. Çalişkan, M. Genç, and S. Servi, "Synthesis, crystal structure, HF and DFT calculations of 1(2-chlorobenzyl)-N-(1-(2-chlorobenzyl)-4,5-dihydro-1Himidazol-2-yl) -1H-benzimidazol-2-amine," Crystallography Reports, vol. 55, no. 7, pp. 1188-1193, 2010.

[23] S. A. Zakaria, S. H. Muharam, M. S. M. Yusof, W. M. Khairul, M. A. Kadir, and B. M. Yamin, "Spectroscopic and structural study of a series of pivaloylthiourea derivatives," Malaysian Journal of Analytical Sciences, vol. 15, no. 1, pp. 37-45, 2011.

[24] C.-R. Lee, T.-H. Tang, L. Chen, and Y. Wang, "A combined experimental and theoretical electron density study of intra- and intermolecular interactions in thiourea S,S-dioxide," Chemistry-A European Journal, vol. 9, no. 13, pp. 3112-3121, 2003.

[25] F. H. Allen, O. Kennard, D. G. Watson, L. Brammer, A. G. Orpen, and R. Taylor, "Tables of bond lengths determined by x-ray and neutron diffraction. Part 1 . Bond lengths in organic compounds," Journal of the Chemical Society, Perkin Transactions, vol. 2, no. 12, pp. S1-S19, 1987.

[26] C. Suksai, C. Pakawatchai, and T. Tuntulani, "Synthesis and crystal structure analysis of thiourea-pendant pyridines," Journal of Chemical Crystallography, vol. 39, no. 5, pp. 348-352, 2009.

[27] A. M. R. Teixeira, H. S. Santos, M. R. J. R. Albuquerque et al., "Vibrational spectroscopy of xanthoxyline crystals and DFT calculations," Brazilian Journal of Physics, vol. 42, no. 3-4, pp. 180-185, 2012.

[28] G. Binzet, G. Kavak, N. Külcü, S. Özbey, U. Flörke, and H. Arslan, "Synthesis and characterization of novel thiourea derivatives and their nickel and copper complexes," Journal of Chemistry, vol. 2013, Article ID 536562, 9 pages, 2013.

[29] P. M. Ushasree, R. Jayavel, C. Subramanian, and P. Ramasamy, "Growth of zinc thiourea sulfate (ZTS) single crystals: a potential semiorganic NLO material," Journal of Crystal Growth, vol. 197, no. 1-2, pp. 216-220, 1999.

[30] A. Saeed, M. F. Erben, and M. Bolte, "Synthesis, structural and vibrational properties of 1-(adamantane-1-carbonyl)-3halophenyl thioureas," Spectrochimica Acta-Part A: Molecular and Biomolecular Spectroscopy, vol. 102, pp. 408-413, 2013. 

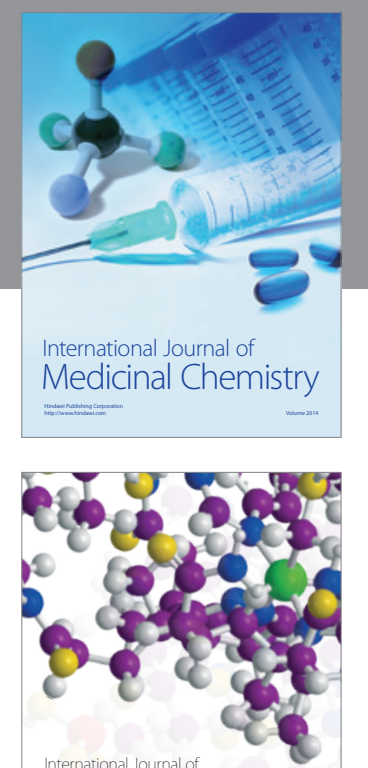

\section{Carbohydrate} Chemistry

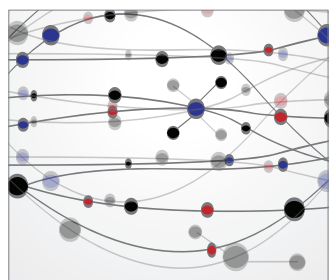

The Scientific World Journal
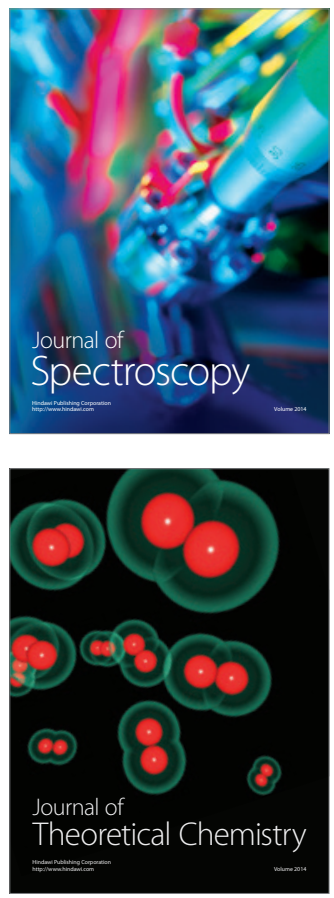
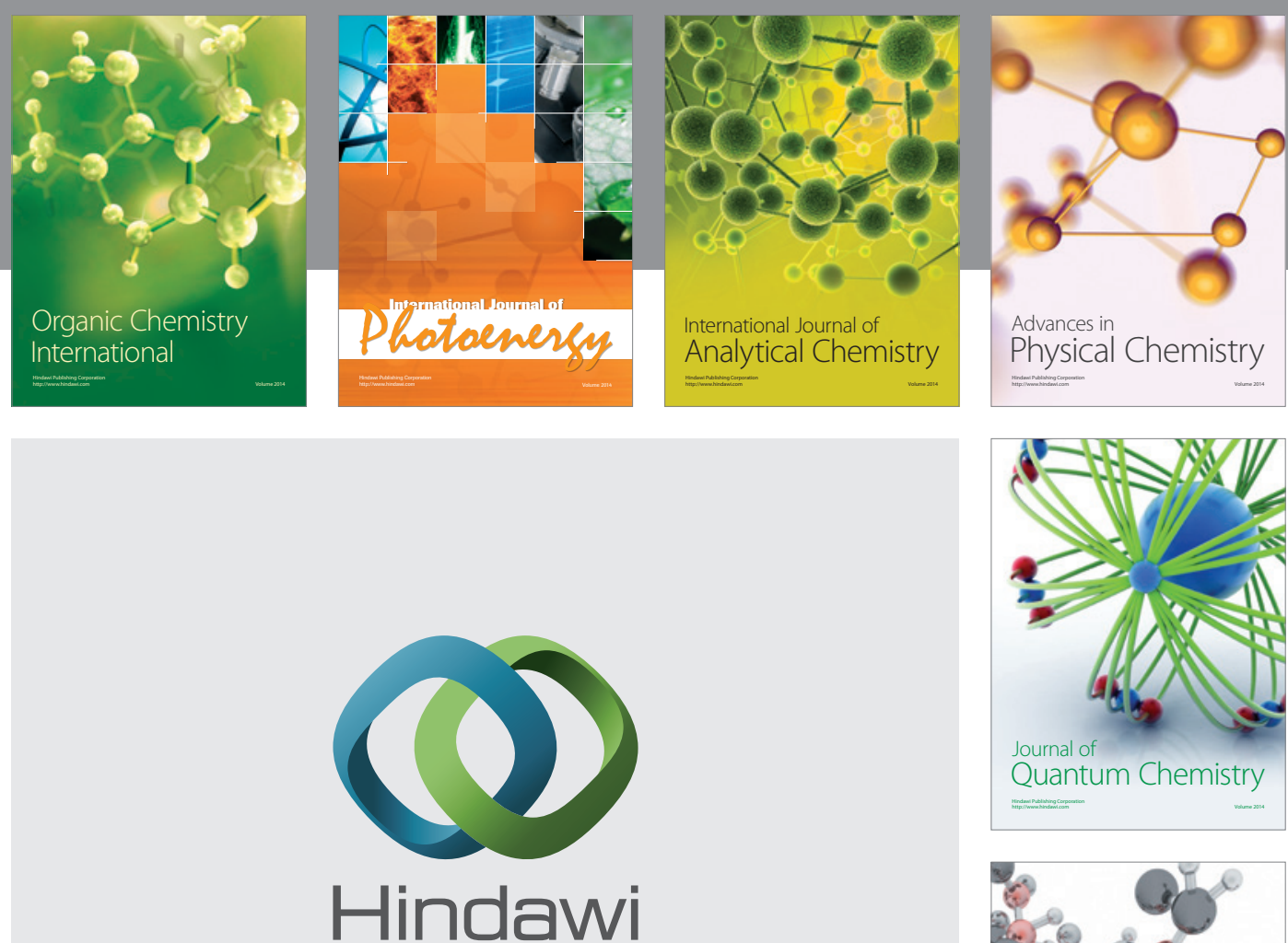

Submit your manuscripts at

http://www.hindawi.com

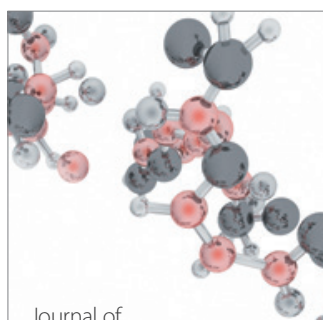

Analytical Methods

in Chemistry

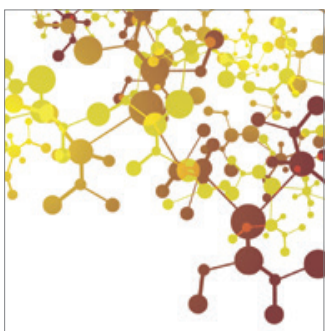

Journal of

Applied Chemistry

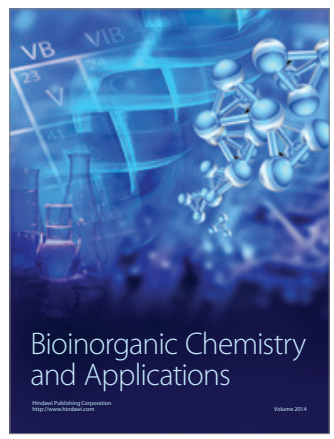

Inorganic Chemistry
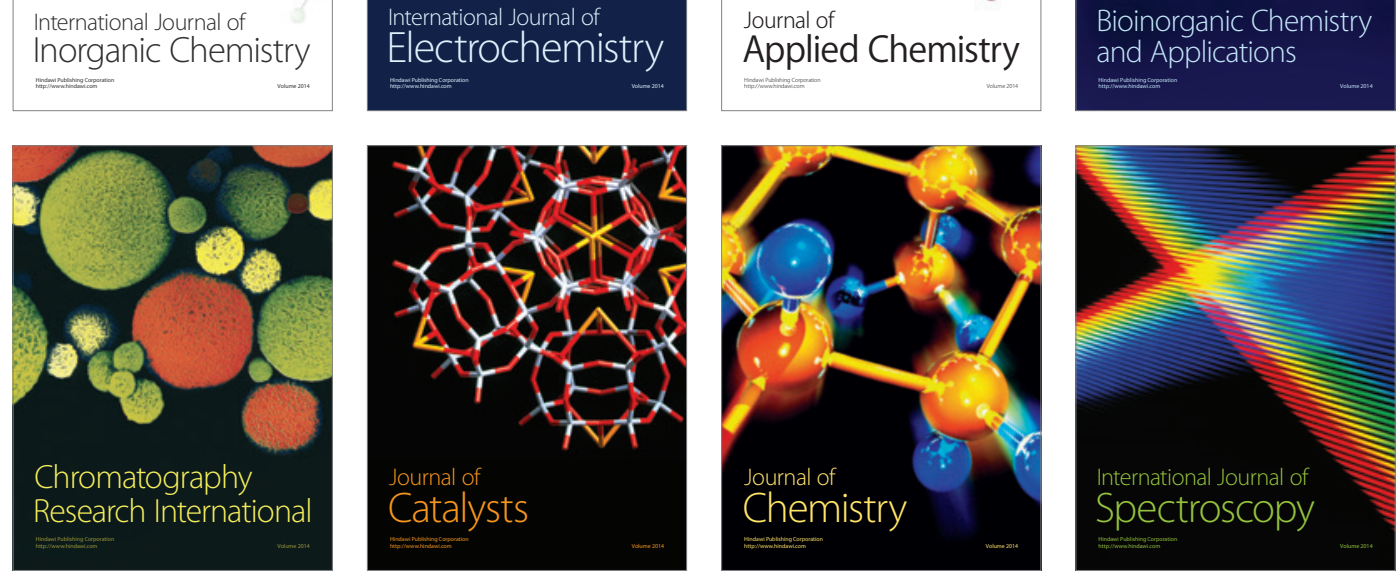